\title{
The art of arboplastics in the landscape architecture
}

\author{
Alexey Koveshnikov ${ }^{1}$, Nina Shiryaeva ${ }^{1}$, Vladimir Naumkin ${ }^{1}$, Karina Bulgakova ${ }^{1, *}$, and \\ Zhanna Silaeva ${ }^{1}$ \\ ${ }^{1}$ Orel State Agrarian University named after N.V. Parakhin, 69, General Rodin str., 302019, Orel, \\ Russia
}

\begin{abstract}
Arbosculpture in Russia is a developing art form. Nowadays there is a small number of works devoted to this topic in our country. In this regard, the aim of the following work is to study the technology of creating arbosculptures in the conditions of the central region of Russia. The material for creating arbosculptures are woody plants of the following species: Fraxinus excelsior L., Acer platanoides L., Prunus cerasifera Ehrh, Prunus cerasus $L$. The formation of sculptures takes 5 years or more. The process of the creation includes such stages as - making a sketch design, selection of a breed, planting a seedling (s), trimming, concrescence/ ingrafting, measures for the care and preservation of a given shape.
\end{abstract}

\section{Introduction}

Creating a comfortable urban environment is an important task of the modern society. Improving the comfort of a person living in the city is possible by maintaining and developing a landscape system. Creating sustainable artificial landscapes is a very painstaking and laborious work. A special role is played by woody plants, which not only improve the microclimatic properties of the environment, but also play a key role in the expressiveness of the landscape-designed space [1-13].

One of the ways to increase the decorativeness of the tree plantations is to create arboplastic sculptures. The tree trunks when they are grafted, bent, trimmed and fused into figures look very decorative, they can become an accent of any park, square or garden.

One of the first significant works related to arbosculpture was a chair planted in 1903 by John Krabsak (USA). Axel Erlandson and his CircusTrees (USA) made a significant contribution to the development of arbosculpture.

Arbosculpture of Russia is a developing art form and is considered to be a new phenomenon in the landscape design. Nowadays there is a small number of works devoted to this topic in our country. In this regard, the aim of the work is to study the technology of creating arbosculptures in the conditions of the central region of Russia.

*Corresponding author: karina-bulgakova@mail.ru 


\section{Materials and methods}

An important part in the landscape design is selection of a species and plant variety used for the formation of the arbosculpture. At the same time, when creating arbosculptures, it is necessary to know perfectly the properties of each tree. Getting started, it is necessary to take into account the speed and rhythm of growth, the features of the natural formation of the crown, the growing conditions.

In this work, the material for creating arbosculptures is woody plants of the following species: European ash (Fraxinus excelsior L.), Norway maple (Acer platanoides L.), myrobalan plum (Prunus cerasiferaEhrh), sour cherry (Prunus cerasus L.). These species are well adapted to the conditions of the central Russia, widely used in the landscaping; they are fast-growing timber trees that are responsive to mechanical formation $[14,15]$.

The technique and timescales of the arbosculpture formation is individual for each species and depend on the variety. The sequence of the work for the creation of arbosculptures includes of the following steps:

- sketch design

- species selection

- planting a seedling (s)

- trimming

- concrescence/ ingrafting

- measures for the care and preservation of a given shape.

\section{Results and discussion}

Basically, the formation of arboplastic sculptures is carried out in spring, because during this period plants experience increased sap flow and due to this, plants grow together much faster.

Large projects, such as a gazebo or a high arch, can take ten years or more, since often it becomes necessary to vaccinate and observe the growth of plants. You can see the shape of a tree in a few years, but the longer it grows, the bigger, more expressive and stronger it becomes.

In order to form a decorative composition called "Cluster" (Fig. 1), the seedlings of European ash at the age of 5-6 years old are used. They are planted at a distance of 30-45 $\mathrm{cm}$ from each other. At a height of 40-55 $\mathrm{cm}$ they are joined together to get one trunk. 5-6 lateral shoots are left, which are bent into rings. Then they are trimmed and joined with the base of the shoots. All excess side shoots are removed with the tree pruner. 

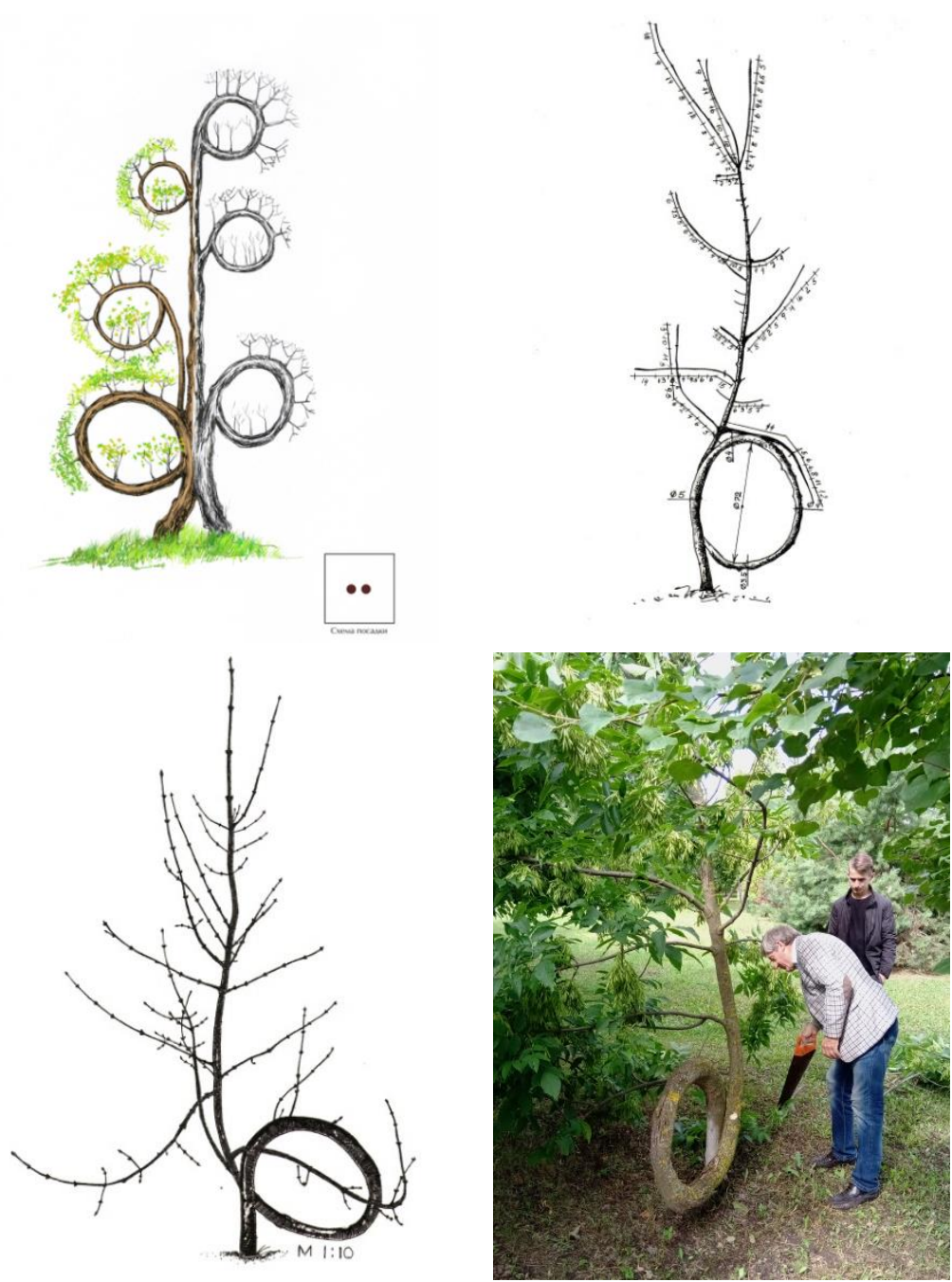

Fig. 1. A decorative composition called "Cluster" of European ash in the arboretum of the Orel State Agrarian University.

Let us give an example of the formation of the Norway maple crown at the age of six (Fig. 2). During the first year we form a four-trunk tree due to the strong trimming. During the second year, the trunks are 1/3 cleaned of the lateral shoots to form the stem. During the third year, each trunk is moved to a horizontal position. To do it, stakes are driven into the ground at the same distance from the centre, ropes made of natural materials are tied to them to keep the shoots in position. To avoid breaking the trunks at the base, they must be tied in the center with a dense cotton tape. During the fourth year, lateral shoots of the 2nd order, reaching $60 \mathrm{~cm}$ or more, are bent into a ring in the growth direction and fixed to the trunk with a cotton tape. We leave one the closest to the center shoot on each trunk. During the fifth year, the shoot left on each side is cut at the same distance and we connect the opposite branches crosswise with a cotton tape. The side shoots that have grown over the year are bent into a ring and fixed with the same tape. 


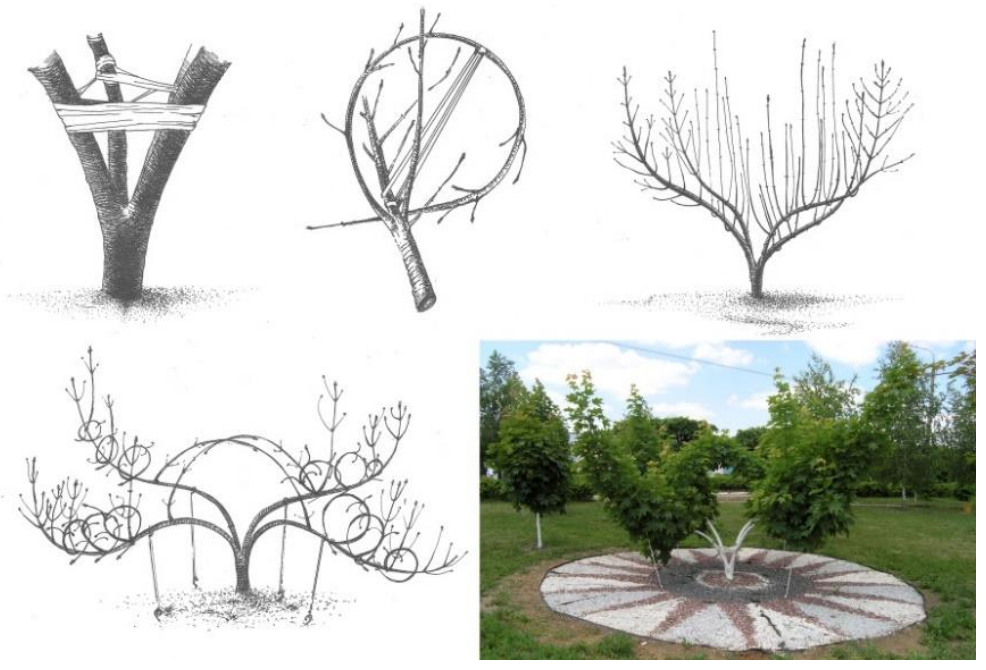

Fig. 2. Decorative composition of the Norway maple on the territory of the arboretum of the Orel State Agrarian University.

The decorative composition "Fairytale Pumpkin" (Fig. 3) is formed from one seedling of the myrobalan plum. During the first year, strong trimming is carried out to increase the number of shoots (up to 8). During the second year of formation, at a height of $15-20 \mathrm{~cm}$ from the ground, the leading shoots are bent by $90^{\circ}$ with the help of load. Then they are bent in the form of "slices", the diameters of which are slightly different for greater decorativeness. As soon as all the trunks meet at one point, they must be joined together. To make the construction stable it is necessary to sprout the side shoots of the leading trunks. Myrobalan plum has a very good shoot-forming ability, so excess branches must be removed well-timed.

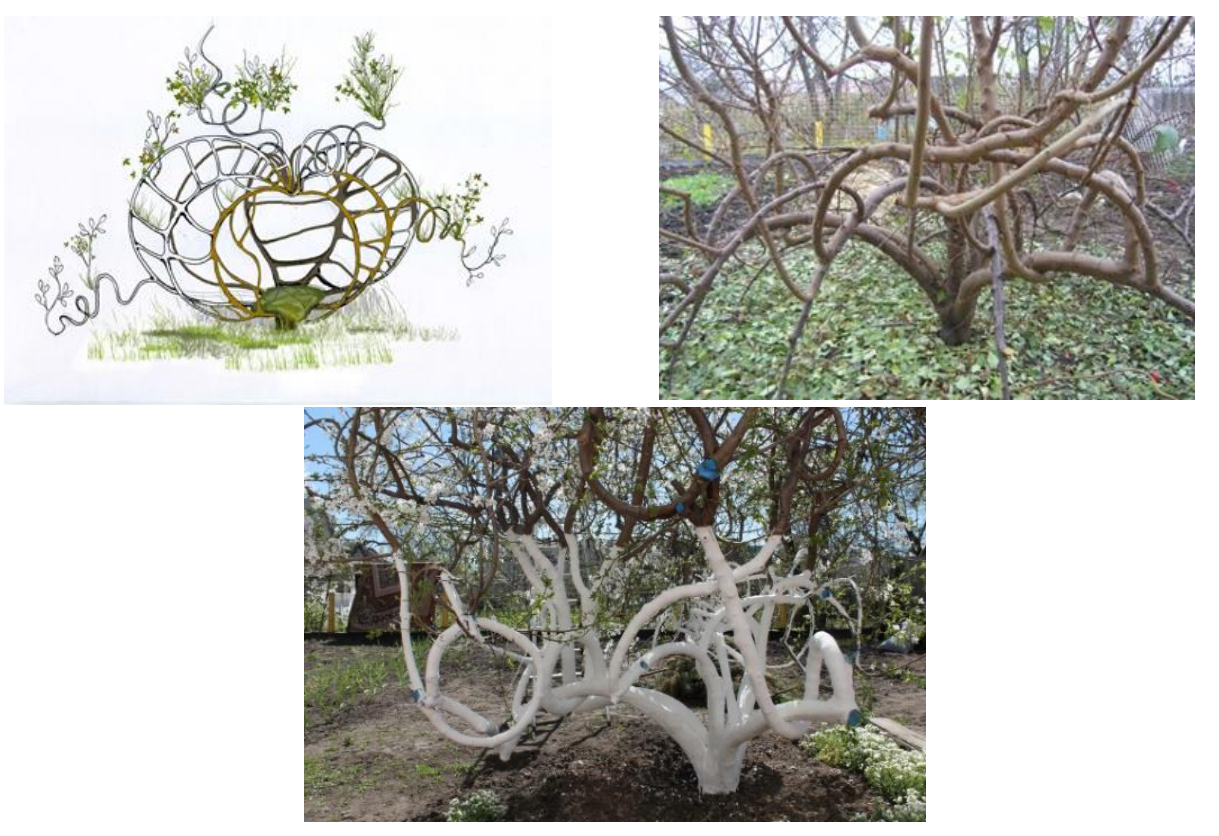

Fig. 3. Decorative composition of myrobalan plum on the territory of the arboretum of the Orel State Agrarian University. 
A composition called "Decorative Bench" (Fig. 4). To create it, it is necessary to plant 30-35 seedlings of sour cherry at the age of 2-3 years old along a wavy line. The height of the stem is $40-45 \mathrm{~cm}$. After that the leading shoots of the plants are bent with a load at an angle of $90^{\circ}$ to the soil. In this direction they grow by $35-40 \mathrm{~cm}$, then again change the direction of growth by $90^{\circ}$ and continue to grow vertically. To make the bends symmetrical in all the plants, a specially welded metal construction is used. To make the structure stronger, the plants are joined together by side shoots at a height of about 1.1-1.2 $\mathrm{m}$. All other side shoots are removed with the tree pruner.

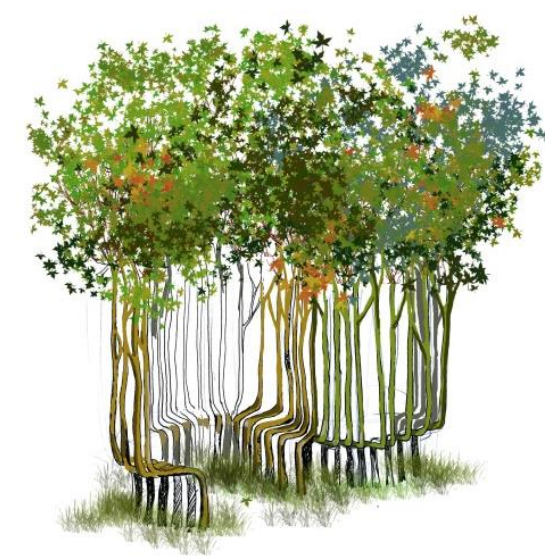

Fig. 4. Decorative composition of sour cherry in the arboretum of the Orel State Agrarian University.

Undoubtedly, arbosculpture can be aesthetically interesting as a form of art. Due to the unique design idea, the possibilities of arbosculpture are expanding: it becomes an element of urban landscaping eco-design (parks, gardens, squares), since it saves time and environmental resources (improves the environment and saves natural resources in the woodworking industry in the manufacture of small architectural forms).

Currently, the authors are developing a fundamentally new area of work with arboplastic forms - the cultivation of decorative details made of wood, which can be used for the designer furniture manufacturing.

\section{References}

1. S. Taylor Lovell, S. DeSantis, C.A. Nathan, M. Breton Olson, W.B. Morris, Agricultural Systems 103, 327-341 (2010) doi.org/10.1016/j.agsy.2010.03.003

2. H. Bo, L. Shu, L. Shu-hua, Procedia Engineering 212011, 414-420 (2011) doi.org/10.1016/j.proeng.2011.11.2033

3. M. Mahdavinejad, M. Abedi, Procedia Engineering 212011, 337-344 (2011) doi.org/10.1016/j.proeng.2011.11.2024

4. A. Leger, W. Oueslati, J. Salanié, Landscape and Urban Planning 116, 13-24 (2013) doi.org/10.1016/j.landurbplan.2013.04.005

5. M.D. Fowler, Design Studies 34, 111-128 (2013) doi.org/10.1016/j.destud.2012.06.001

6. C. von Haaren, B. Warren-Kretzschmar, C. Milos, C. Werthmann, Landscape and Urban Planning 130, 159-170 (2014) doi.org/10.1016/j.landurbplan.2014.06.012

7. A. Misni, Procedia - Social and Behavioral Sciences 22223, 693-701 (2016) doi.org/10.1016/j.apcbee.2014.10.058 
8. D.Ruggeri, D. Young, Frontiers of Architectural Research 5, 15-26 (2016) doi.org/10.1016/j.foar.2015.12.001

9. R.M. Perkl, Landscape and Urban Planning 156, 44-58 (2016) doi.org/10.1016/j.landurbplan.2016.05.016

10. S.A. Matovnikov, N.G. Matovnikova, Procedia Engineering 1502016, 1966-1971 (2016) doi.org/10.1016/j.proeng.2016.07.199

11. R. Coles, S. Costa, Landscape and Urban Planning 170, 1-5 (2018) doi.org/10.1016/j.landurbplan.2017.10.003

12. Julien Carlier, James Moran, Journal of Environmental Management 2471, 790-803 (2019) doi.org/10.1016/j.jenvman.2019.06.116

13. N.L. Haan, Y. Zhang, D.A. Landis, Trends in Ecology \& Evolution 35, 175-186 (2020) doi.org/10.1016/j.tree.2019.10.003

14. A. Koveshnikov, N. Shiryaeva, M. Stavtsev, Bulletin of the Oryol State Agrarian University 2(53), 36-44 (2015)

15. O. Smolina, IOP Conference Series: Materials Science and Engineering The conference proceedings ICCATS-2019 (South Ural State University, Irkutsk National Research Technical University, Ural Federal University named after the first President of Russia B.N. Yeltsin, 2019) 